\title{
PV Panelinin Altına Serbest Olarak Yerleştirilen Siyah Emici Plakanın Termal Kapasitesinin Belirlenmesi
}

\author{
Determination of Thermal Capacity of Black Absorber Plate that Freely Placed to Beneath of the \\ PV Panel
}

\author{
Mustafa ATMACA ${ }^{1}$ iD, İmdat Zafer PEKTEMIR ${ }^{2}$ iD \\ ${ }^{1}$ Marmara Üniversitesi, Teknoloji Fakültesi, Makine Mühendisliği Bölümü, 34722, İstanbul, Türkiye \\ ${ }^{2}$ Marmara Üniversitesi, Fen Bilimleri Enstitüsü, 34722, İstanbul, Türkiye
}

Öz

Fotovoltaik termal sistemler, aynı yüzeyden hem termal hem elektrik enerjisi kazanmak için oldukça popülerdir. Bu çalısmada, PV panelin altına yerleştirilmiş siyah boyalı absorber plakanın 1sı kazancı deneysel olarak araştırılmıştır. Bu amaçla bakır borulu bir 1sı değiştirici dizayn edilmiştir. Ayrıca siyah boyalı bir alüminyum emici plaka dizayn edilerek absorber ve 1 sıı değiştirici ısıl iletken bir yapıştırıcı sayesinde birleştirilmiştir. En sonunda absorber, PV panelin arkasına yerleştirilmiş ve 1 s1 yalıtım malzemesi ile yalıtılmıştır. Ayrıca sistem, bir su 1sıtma sistemi ile birleştirilmiş olup absorber plakanın 1sı kazancı farklı iklim koşulları için araştırılmıştır. Araştırma, farklı güneş 1şınımı, çevre sıcaklığı ve rüzgar hızları için yürütülmüştür.Sonuçlar, soğutmadan önce, absorber plaka sıcaklığının $70-80^{\circ} \mathrm{C}$ seviyelerine ulaştığını göstermiştir. Ayrıca absorberin iyi oranda termal güneş enerjisi kazandığı görülmüştür. Bu enerji kolaylıkla su 1sıtma sistemlerinde kullanılabilir. Ayrıca, su 1sıtma sistemi sayesinde absorber sıcaklığının optimum değerlere düşürülebileceği görülmüş̧ür.

Anahtar Kelimeler: Fotovoltaik, Emici levha, Termal sistemler, Güneş ışınımı

\begin{abstract}
Photovoltaic - thermal systems are very popular for gaining both thermal and electrical energy from same surface. In this study, thermal gain of black colored absorber plate that placed at beneath of PV panel was investigated experimentally. For this purpose, it was designed that copper tubes heat exchanger. Also it was designed that a black painted aluminum absorber plate. Absorber and heat exchanger were joined by means of thermally conductive adhesive. Finally, absorber was placed to beneath of the PV panel and it was insulated using heat insulation material. Also absorber system was integrated with a water heating system. Thermal gain of absorber plate was investigated for different climatic conditions. Research was conducted for different solar irradiance, ambient temperature, wind speed, relative humidity values. Results show that absorber temperature reaches up to $70-80^{\circ} \mathrm{C}$ before the cooling. Also it has been seen that absorber, gained well amount solar thermal energy. This energy can be used for water heating systems easily. Also it has been seen that absorber temperature can be decrease to optimum value by means of water heating system.
\end{abstract}

Keywords: Photovoltaic, Absorber plate, Thermal systems, Solar irradiance

\section{GíRiş}

Enerji, hayatımızın önemli parçalarından biri fakat enerji kaynakları sınılıdır. Yenilenebilir enerji kaynaklarının daha fazla kullanımı bu sorun için bir çözüm olabilir. Başlıca yenilenebilir enerji kaynağı olan güneş enerjisinin uygulamaları iki ana bölümden oluşmaktadır. Birincisi PV paneller sayesinde elektrik üretimidir. Diğer türü ise, termal kolektörler sayesinde termal enerji üretimidir. Ayrıca bu alanda, fotovoltaik-termal (PV/ T) sistemler vardır. Bu sistemler, fotovoltaik panel ve ona entegre edilmiş $1 s ı$ değiştirici ünitelerden oluşur. 
Güneş pilleri yüksek güneş radyasyonuna maruz kaldığında daha fazla elektrik üretir, sıcaklığı arttığında verimi düşer. Sonuçlar, bir hibrit PV/T modülün elektrik üretiminin, artan panel sıcaklığı ile azaldığını göstermektedir [1].

İşletme sıcaklığı, fotovoltaik süreçlerde önemli bir yere sahiptir [2]. PV panellerin elektriksel verimi çalışma s1caklığına bağlıdır, performansın iyileştirilebilmesi için efektif soğutma gerekir [3]. Rawat ve arkadaşları [4] bakır absorber plaka kullanılansu bazlı bir PV/T sistem üzerinde çalışmışlar ve PV/T sistemin elektriksel ve termal performansının PV modül performansına göre daha fazla olduğunu tespit etmişlerdir.İşte fotovoltaik-termal (PV/T) sistemler, artan PV panel sıcaklığını düşürmesinin yanısıra, farklı şekillerde enerji dönüşümlerine olanak sağlarlar. Bu sistemlerin başlıcaları, hava esaslı ve su esaslı sistemlerdir.

Soni ve arkadaşları [5] su bazlı bir PV/T sistem üzerinde çalışmışlar ve soğutma yapılmadığında maksimum PV panel sıcaklığını $79.31{ }^{\circ} \mathrm{C}$ bulmuşlar, optimum debi değeriyle soğutma yapıldığında ise, PV panel sıcaklığının $47.13{ }^{\circ} \mathrm{C}$ değerine düştüğünü tespit etmişlerdir.

$\mathrm{Bu}$ çalışmada, bir su esaslı PV/ T sisteme entegre edilen siyah emici yüzeyin isıl kapasitesi belirlenmeye çalışılmıştır. Bu 1sıl kapasite, güneş radyasyonu ile birlikte diğer meteorolojik değişkenlere doğrudan bağlıdır. Meteorolojik değişkenlere bağlı olarak, PV panellerin s1caklığını belirlemek için çeşitli çalışmalar yapılmıştır. Örneğin, Muzathik [6], rüzgar hızının da hesaba katıldığı aşağıdaki formülasyonu ortaya koymuştur.

$\mathrm{T}_{\text {modul }}\left({ }^{\circ} \mathrm{C}\right)=0,943 \times \mathrm{T}_{\text {amb. }}+0,0195 \times$ Irridance-1,528xWindspeed $+0,3529$

$\mathrm{Bu}$ formülasyonda, üç önemli meteorolojik parametre olan, hava sıcaklığı, güneş radyasyonu ve rüzgar hızına bağlı olarak modül sıcaklığının değişimi incelenmiştir.

Meteorolojik parametrelere bağlı olarak, artan panel s1caklığının azaltılması ve kazanılan enerjinin su 1sıtma sistemlerinde kullanımı ile ilgili çeşitli çalı̧̧malar yapılmıştır.

Kalogirou ve Tripanagustopoulos [7] yaptıkları çalışmada, tipik bir termal güneş kolektörüne entegre ettikleri amorf silikon ve polikristal güneş pilleri ile, doğal dolaşımlı ve cebri dolaşımlı su ısıtma üniteleri kullanarak, sistemlerin elektriksel ve termal enerji kazançlarının belirlenmesi üzerine çalışmışlardır. Çalışma sonuçlarına göre; cebri dolaşımlı aktif sistem performansının doğal dolaşımlı sisteme göre oldukça yüksek olduğu görülmüştür.
Güneş enerjisi kazancı, konuma bağlı olarak \%60 ve \%87 arasında değişmektedir. Hibrid olmayan PV sistem \%38 civarında fazla elektrik üretmesine rağmen bu sistem, binaların sıcak su ihtiyacını yüksek oranda karşılayabilme özelliğine sahiptir.

Rekha ve arkadaşları [8] yaptıkları, çalışmada, düzlemsel güneş kolektörü ile iyileştirilmiş bir PV/T sistemin, 1sıl, elektriksel ve ekserji performansını sayısal olarak araştırmışlardır. Çalışma sonucunda, ortalama toplam elektriksel, enerji ve ekserji verimleri sirasıyla; $11 \%, 63 \%$ ve $15 \%$ olarak belirlenmiştir. Bir başka çalışmada Hossain ve arkadaşları [9] paralel serpantin borulu bir su bazlı PV/T sistem üzerinde çalışmışlar ve sistemin maksimum termal verimini $76.58 \%$ bulmuşlardır.

Bu çalışmada, PV panelin arkasına yerleştirilen siyah boyalı absorber plakanın termal kazanımı belirlenmeye çalışılmıştır. Deneylerin yürütüldüğü atmosferik koşulların değişimi de şekillere aktarılarak, bu konuda yapılacak çalışmalara 1şık tutulmaya çalışılmıştır.

\section{MATERYAL VE METOT}

Bu çalışmada, siyah boyalı alüminyum plaka ile bakır ısı değiştirici, $0.88 \mathrm{~W} / \mathrm{mK}$ ssıl iletkenlik değerine sahip 1sıl iletken bir yapıştırıcı ile birleştirilerek bir absorber ünite oluşturulmuştur. Siyah boyalı alüminyum plaka, yapıştırıcının daha düzgün yayılabilmesi için, şekil 1' de görüldüğü gibi üç parça halinde su serpantini ile birleştirilmiştir. Absorber ünite, bir monokristal PV panelin altına serbest olarak yerleştirilmiştir ( Şekil 2 ). Sistem, 33 eğimli bir platform üzerine sabitlenmiş ve $50 \mathrm{~mm}$ kalınlığında ve $0.035 \mathrm{~W} / \mathrm{mK}$ is1 iletkenlik değerine sahip, taş yünü esaslı yalıtım malzemesi ile yalıtılmıştır. Tablo 1'de kullanılan malzemeler ve özellikleri görülmektedir.

Tablo 1. Deney seti temel parça özellikleri

\begin{tabular}{|l|l|l|}
\hline No & Adı & Özellikler \\
\hline $\mathbf{1}$ & PV panel & $\begin{array}{l}\text { TPSM6U Monocristalline } 200 \mathrm{~W}, \mathrm{~V}_{\text {oc }}: 45.4 \\
\text { V,I }_{\text {sc }}: 5.77,808 \times 1580 \mathrm{~mm}\end{array}$ \\
\hline $\mathbf{2}$ & Absorber plaka & $\begin{array}{l}\text { Alüminyum, } 0.4 \mathrm{~mm}, \text { siyah boyalı, } \\
808 x 1580 \mathrm{~mm}\end{array}$ \\
\hline $\mathbf{3}$ & Su serpantini & $\begin{array}{l}\text { Bakır }(\lambda: 394 \mathrm{~W} / \mathrm{mK}) \text { kolektör çapı: } \\
32 \mathrm{~mm}, \text { boru çapı: } 10 \mathrm{~mm}\end{array}$ \\
\hline $\mathbf{4}$ & Boyler & Isı değiştirici serpantinli, $100 \mathrm{lt}$ \\
\hline $\mathbf{5}$ & Pompa & Frekans konvertörlü \\
\hline
\end{tabular}




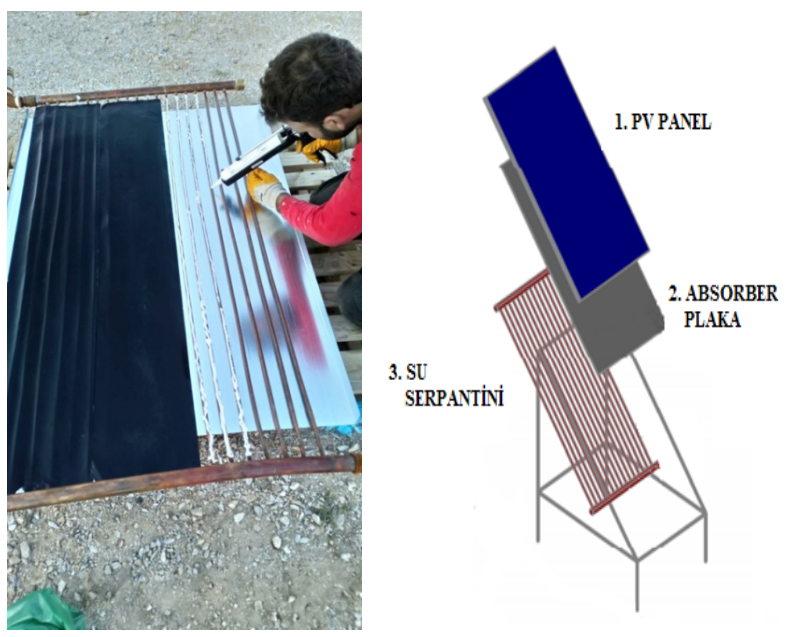

Şekil 1. Absorber montaj1 Şekil 2. Deney seti montaj şemas1

Absorber ünite, şekil 3'de görüldüğü gibi su 1sıtma devresi ile irtibatlandırılmıştır. Su 1sıtma devresi, boyler, pompa, vanalar ve boru hattından oluşmaktadır. Ayrıca bir genleşme deposu, boyler serpantin seviyesini aşacak şekilde yerleştirilmiştir ( Şekil 3 ).Tablo 1'de de belirtildiği gibi serpantin malzemesi olarak ısıl iletkenliği $394 \mathrm{~W} / \mathrm{mK}$ olan bakır borular kullanılmıştır. Dağıtıcı borular $10 \mathrm{~mm}$, alt ve üst kolektörler ise $32 \mathrm{~mm}$ çapında seçilmiş̧ir. Absorber plaka ise; siyah boyalı alüminyumdan imal edilmiştir.

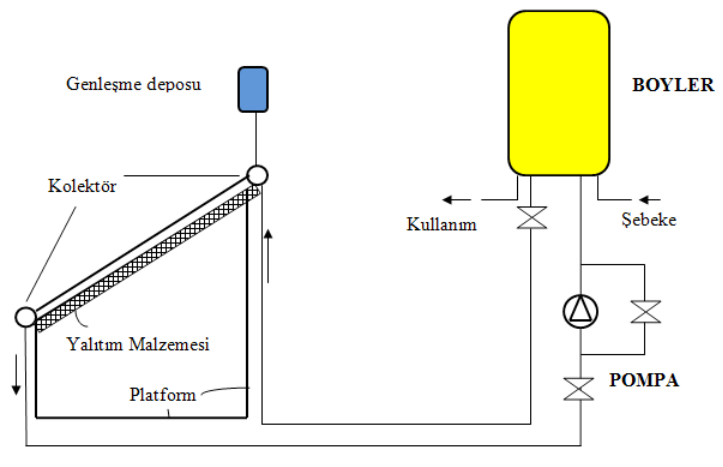

Şekil 3. Su 1sıtma devresi şeması

Isı değiştirici akışkan olarak, donma riskine karşı, 1/3 oranında etilen glikol ( antifiriz ) içeren su - antifiriz karışımı kullanılmıştır. Bu orandaki karışımın özgül 1sısı ve yoğunluğu, Duffie ve Beckman [10] tarafindan yapılan çalışma baz alınarak, $20-40{ }^{\circ} \mathrm{C}$ için yaklaşı; $\mathrm{C}_{\mathrm{p}}=3700 \mathrm{j} / \mathrm{kg}^{\circ} \mathrm{C}=$ $0.885 \mathrm{kcal} / \mathrm{kg}{ }^{\circ} \mathrm{C}, \rho=1050 \mathrm{~kg} / \mathrm{m}^{3}$ olarak alınmıştır.

Tablo 2'de veri alma cihazlarının özellikleri ve Şekil 4'de bilgi algılama sistemi ve sensör yerleşimi görülmektedir. Veri alma sisteminde; veri alma cihazlarından alınan veriler, analog 4-20 mA, Pt 100, mV okuma kabiliyetine sahip endüstriyel modüllere aktarılmaktadır. Modüller bu verileri, okunarak bilgisayar diline çevrilmesi için, RS-485 Modbus RTU protokolüne çevirmektedir. Bilgisayara aktarılan veriler ise bir program vasıtasıyla raporlanıp değerlendirilmektedir.

Tablo 2. Veri alma cihaz özellikleri

\begin{tabular}{|c|c|c|c|}
\hline No & Adı & Yerleștirilme șekli & Özellikler \\
\hline 1 & $\begin{array}{l}\text { Sicaklık } \\
\text { sensörü }\end{array}$ & $\begin{array}{l}\text { Su serpantini giriş, çıkışına } \\
\text { ve absorber plakanın merkez } \\
\text { noktasına yerleştirildi. }\end{array}$ & Pt 100 \\
\hline 3 & Piranometre & $\begin{array}{l}\text { PV açısıyla aynı olacak şe- } \\
\text { kilde } 33^{\circ} \text { eğimli olarak yer- } \\
\text { leştirildi. }\end{array}$ & $\begin{array}{l}\text { EKO MS }-410 \\
\text { Hassasiyet } 11.78 \\
\mu \mathrm{V} / \mathrm{Wm}^{-2} 2,0-2000 \\
\mathrm{~W} / \mathrm{m}^{2}\end{array}$ \\
\hline 4 & $\begin{array}{l}\text { Diş hava } \\
\text { nem ve s1- } \\
\text { caklık sen- } \\
\text { sörü }\end{array}$ & $\begin{array}{l}\text { Güneş ışıllarına doğrudan } \\
\text { maruz kalmayacak şekilde, } \\
\text { yerden } 1 \text { m yukarıa yerleş- } \\
\text { tirildi. }\end{array}$ & $\begin{array}{l}\text { Sıcaklık ve nem } \\
\text { için iki farklı ana- } \\
\text { log çıkışa sahip. }\end{array}$ \\
\hline 5 & $\begin{array}{l}\text { Rüzgar hız } \\
\text { sensörü }\end{array}$ & $\begin{array}{l}\text { PV panelin üst kenarı seviye- } \\
\text { sine yerleştirildi. }\end{array}$ & $\begin{array}{l}\text { Encoder pulse' leri } \\
\text { 4-20 mA akıma } \\
\text { çevrilmektedir. }\end{array}$ \\
\hline
\end{tabular}

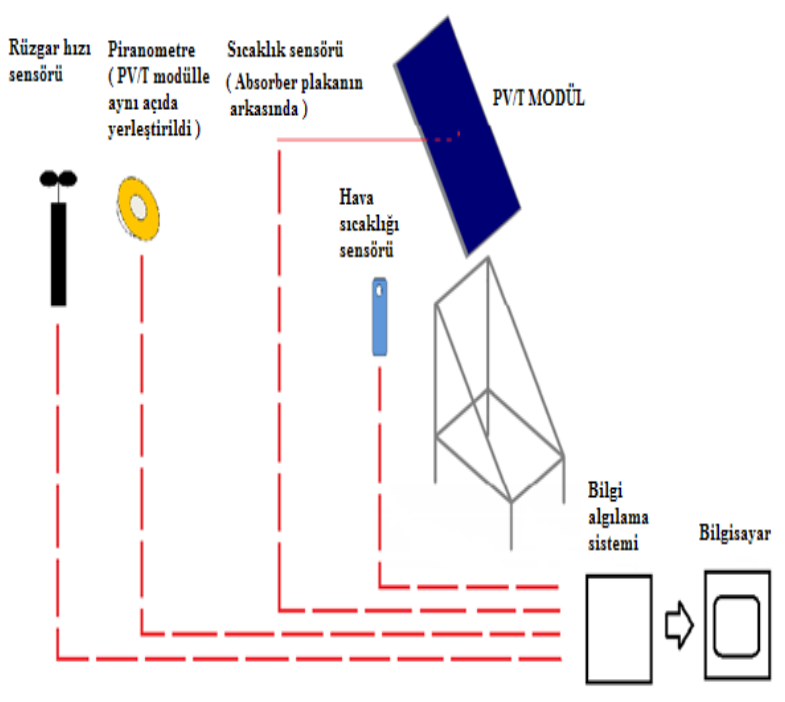

Şekil 4. Bilgi algılama sistemi ve sensör yerleşimi $[11,12]$

\section{BULGULAR}

Çalışmalar, $37^{\circ} \mathrm{N}$ enlemi ile $32^{\circ} \mathrm{E}$ meridyenindeki Konya İli’nde, Şubat ve Mart ayları içerisinde farklı meteorolojik parametrelere sahip günlerde yürütülmüştür. Ölçümler, soğutmadan önce absorber sıcaklı̆̆ının oldukça yüksek olduğunu ve soğutma işlemiyle sıcaklığının optimum değerlere 
düşürülebildiğini göstermektedir ( Şekil 5 ). Tablo 3'den anlaşılacağı üzere, ele alınan her üç günün, termal dönüşüm oranı ortalaması yaklaşı \% 50 seviyesinde olmuştur. İletim boruları yalıtımsız olduğu için iletim hattından havaya 1S1 transferi oldukça yüksek seviyededir. Bu boruların yalıtılması ile birlikte boyler toplam 1sı kazancı artacak, iletim hattından havaya olan 1Sı transferi azalacaktır.

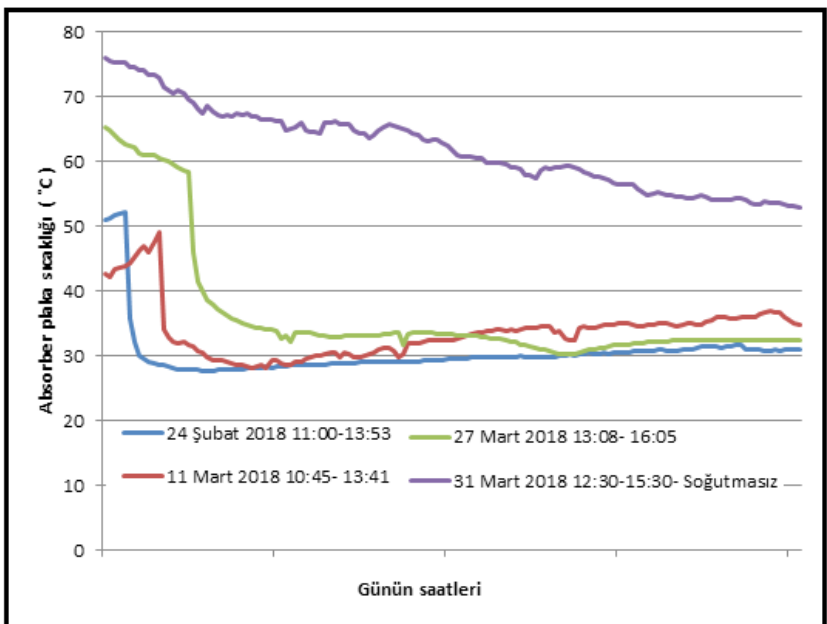

Şekil 5. Soğutması gün ve soğutma yapılan günlerdeki absorber plaka sıcaklıklarının karşılaştırılması.

Boyler toplam 1s1 kazanc1: $\mathrm{Q}_{\text {boy }}=\mathrm{m} \mathrm{C}_{\mathrm{p}}\left(\mathrm{T}_{\mathrm{s}}-\mathrm{T}_{\mathrm{i}}\right)$

Boyler 1s1 kazanc1 $\mathrm{q}_{\text {boy }}=\left(\left(\mathrm{Q}_{\text {boy }} /\right.\right.$ toplam saat $\left.) / 860\right) 1000$

Ortalama boru hattı sıcaklığı: $\mathrm{T}_{\text {ort }}=\left(\mathrm{T}_{\mathrm{g}}+\mathrm{T}_{\mathrm{c}}\right) / 2$

Boru hattından havaya 1sı kaybı $\mathrm{q}_{\mathrm{b}-\mathrm{h}}=2 \pi \mathrm{L} \lambda\left(\mathrm{T}_{\text {ort }}-\mathrm{T}_{\mathrm{h}}\right) / \ln ($ $\left.\mathrm{r}_{2} / \mathrm{r}_{1}\right)$

( Boru hattı özellikleri: $\mathrm{L}=20 \mathrm{~m}, \varnothing 32 \times 5,4 \mathrm{~mm}$ PP-R 80 PP3 boru $\lambda=0.24 \mathrm{~W} / \mathrm{mK}$, boru hattı yalıtılmamıştır.)

Absorberden çekilen 1s1: $q_{t}=q_{b o y}+q_{b-h}$

Termal dönüşüm oranı: $\eta_{\mathrm{th}}=\mathrm{q} /\left(\right.$ Ix $\left.\mathrm{A}_{\mathrm{p}}\right)$

Tablo 3. Farklı günlere ait termal değerlerin karşıllaştırılması

\begin{tabular}{|l|l|l|l|}
\hline Parametre & $\begin{array}{l}\mathbf{2 4} \text { Şubat 2018 } \\
\mathbf{1 1 : 3 0 - 1 4 : 3 0}\end{array}$ & $\begin{array}{l}\mathbf{1 1} \text { Mart 2018 } \\
\mathbf{1 1 : 0 0 - 1 4 : 0 0}\end{array}$ & $\begin{array}{l}\mathbf{2 7} \text { Mart } \\
\mathbf{2 0 1 8} \\
\mathbf{1 3 : 4 0 - 1 8 : 4 0}\end{array}$ \\
\hline $\begin{array}{l}\text { Ortalama absorber } \\
\text { plaka } \\
\text { Sicaklığ }\left({ }^{\circ} \mathrm{C}\right)\end{array}$ & 29.97 & 33.03 & 31.19 \\
\hline $\begin{array}{l}\text { Ortalama soğutma } \\
\text { suyu giriş } \\
\text { Sicaklığ }\left({ }^{\circ} \mathrm{C}\right)\end{array}$ & 22.60 & 22.58 & 24.79 \\
\hline $\begin{array}{l}\text { Ortalama soğutma } \\
\text { suyu çıkış } \\
\text { sicaklığ }\left({ }^{\circ} \mathrm{C}\right)\end{array}$ & 23.51 & 24.33 & 28.98 \\
\hline
\end{tabular}

\begin{tabular}{|l|l|l|l|}
\hline $\begin{array}{l}\text { Ortalama hava sıcak- } \\
\text { lı̆̆ }\left({ }^{\circ} \mathrm{C}\right)\end{array}$ & 16.03 & 17.13 & 23.73 \\
\hline $\begin{array}{l}\text { Ortalama 1şınım de- } \\
\text { ğeri }\left(\mathrm{W} / \mathrm{m}^{2}\right)\end{array}$ & 1142.03 & 1152.09 & 581.93 \\
\hline $\begin{array}{l}\text { Ortalama rüzgar hızı } \\
(\mathrm{m} / \mathrm{s})\end{array}$ & 2.66 & 1.41 & 3.21 \\
\hline $\begin{array}{l}\text { Boyler ilk sıcaklığ1 } \\
\left({ }^{\circ} \mathrm{C}\right)\end{array}$ & 11.80 & 18.80 & 17.60 \\
\hline $\begin{array}{l}\text { Boyler son sıcaklığ1 } \\
\left({ }^{\circ} \mathrm{C}\right)\end{array}$ & 19.80 & 24.10 & 23.90 \\
\hline $\begin{array}{l}\text { Boyler toplam 1sı ka- } \\
\text { zanc1 ( kcal) }\end{array}$ & 708 & 530 & 630 \\
\hline $\begin{array}{l}\text { Boyler 1s1 kazanc1 } \\
(\text { W })\end{array}$ & 274.42 & 463.43 & 230.98 \\
\hline $\begin{array}{l}\text { Boru hattından ha- } \\
\text { vaya 1s1 kayb1 } \\
(\text { W })\end{array}$ & 514.32 & 668.86 & 377.49 \\
\hline $\begin{array}{l}\text { Absorberden çekilen } \\
\text { 1s1 ( W })\end{array}$ & 788.74 & 54.38 & 51.07 \\
\hline $\begin{array}{l}\text { Termal dönüşüm } \\
\text { oranı ( \% })\end{array}$ & 541 & 146.51 \\
\hline
\end{tabular}

Şekil 6 da; 24 Şubat 2018, Şekil 7 de; 11 Mart 2018 ve Şekil 8 de; 27 Mart 2018 gününe ait absorber plaka termal kazancını etkileyen, termal ve meteorolojik parametrelerin değişimleri görülmektedir. Bu şekillerde sağda yer alan birincil düşey eksende $\mathrm{W} / \mathrm{m}^{2}$ cinsinden güneş ışınımı, solda yer alan ikincil düşey eksende ise, ${ }^{\circ} \mathrm{C}$ cinsinden sıcaklık skalası yer almaktadır. Yatay eksen ise, gün içinde deneysel verilerin alındığ 1 saatleri göstermektedir. 24 Şubat ve 11 Mart günleri ele alınan saatler, güneş 1şınımının en yüksek olduğu öğlen saatleri iken, 27 Mart günü öğleden sonrayı da tam kapsayacak şekilde seçilmiştir. 27 Mart günü, ortalama rüzgar hızı ve ortalama hava sıcaklığı diğer günlerden fazladır. Her üç durumda da, absorber plakanın ısı kazanımının ortalama 1ş1nım değerine oranı, 50 \% seviyelerine yakın olarak gerçekleşmiştir. 11 Mart ve 27 Mart günleri gün boyunca, bulutluluk nedeniyle güneş 1şınımında dalgalanmalar oluşmuştur( Şekil 7 ve 8 ). 24 Şubat günü ise 13:30 dan sonra kısmen ış1nım dalgalanmaları oluşmuştur ( Şekil 6 ). Her üç durumda da meteorolojik parametreler değişkenlikler göstermekle birlikte, absorber plaka sıcaklıklarının $30-35^{\circ} \mathrm{C}$ civarında olduğu görülmektedir ( Şekil 6-8 ). 50 mm yalıtım uygulanmış olması, absorber sıcaklığını daha kararlı hale getirmiş̧ir. Kesin sayısal sonuç elde etmekten ziyade, montaj ve uygulama tekniği açısından, bu alanda yapılacak çalışmalara ışık tutmak amaçlandığından, belirsizlik analizi yapılmasına gerek duyulmamıştır. 


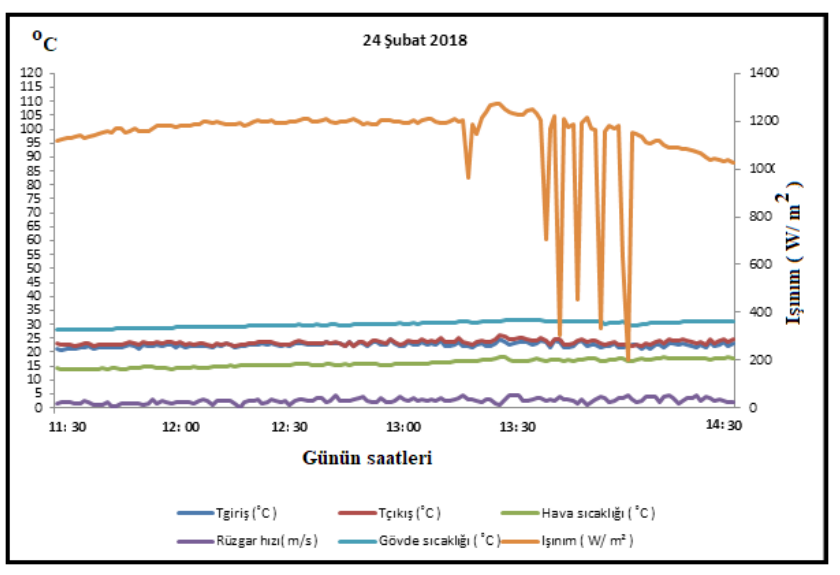

Şekil 6. 24 Şubat 2018 11:30 - 14:30 arasında elde edilen değerler.

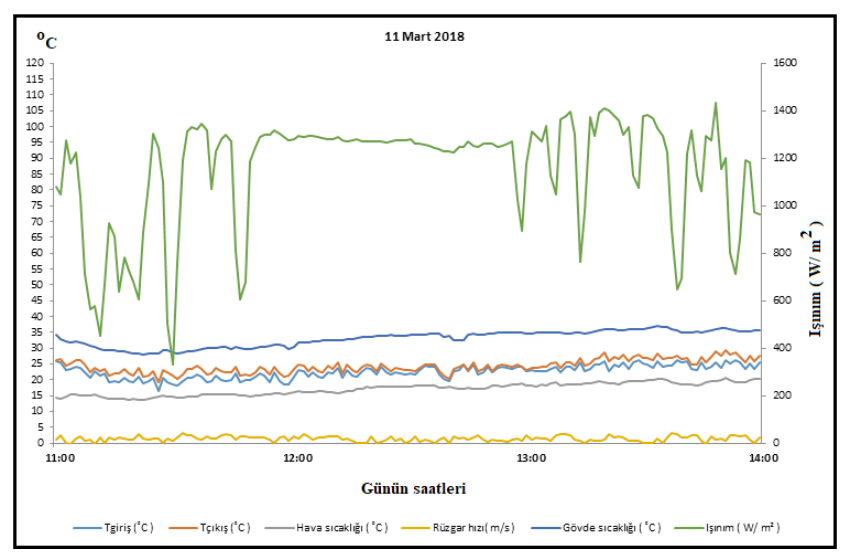

Şekil 7. 11 Mart 2018 11:00 - 14:00 arasında elde edilen değerler.

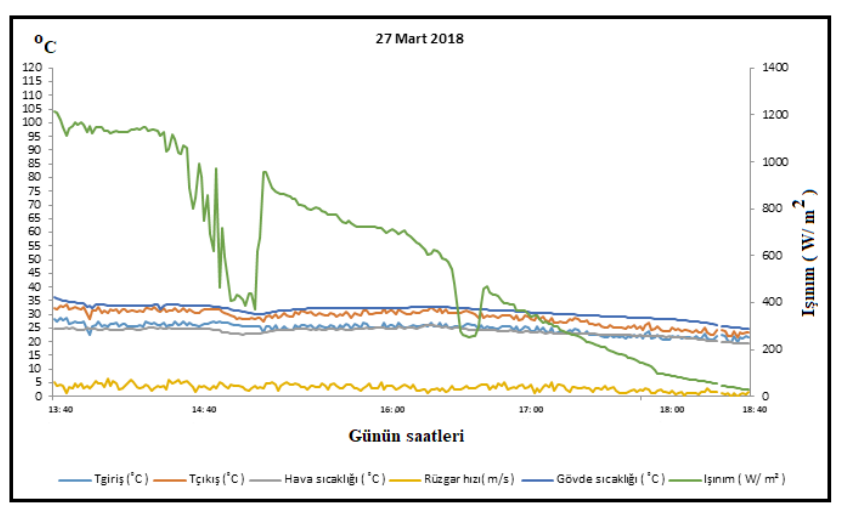

Şekil 8. 27 Mart 2018 13:40 - 18:40 arasında elde edilen değerler.

\section{SONUÇLAR}

Yapılan çalışma, PV panelin arkasına serbest olarak yerleştirilen siyah boyalı plakanın oldukça yüksek sıcaklıklara ulaştığını ve PV/T sistemlerde kolaylıkla kullanılabileceğini göstermektedir. Uygulanan hesap metoduna göre, absorber plaka 1sı kazanımı, incelenen her üç günün ortalaması alınırsa 50\% olarak gerçekleşmiştir. Soğutma işlemi ile, sıcaklık optimum PV çalışma sıcaklığı seviyelerine düşürülebilir ve kazanılan termal enerji su 1sitma sistemlerinde kullanılabilir. Bu çalışmada, sadece termal kazanım incelenmekle birlikte, bu şekilde yapılacak bir uygulama ile, aynı alandan hem elektriksel hem de termal enerji kazanılacağından, toplam verim oldukça yükssek olacaktır. Sıcak su iletim hatlarına, boyler 1sı transfer oranının yetersiz kalabileceği düşünülerek ilk etapta yalıtım yapılmamıştır. Yalıtım yapılmış olsayd1, boylerden kullanım suyuna 1sı transferi artacağından boyler suyu, kullanım için optimum değerlere çıkarılabilecekti. Sonuçlar, bu şekilde bir uygulama ile oldukça iyi termal kazanım elde edilebileceğini göstermektedir.

\section{TERMINOLOJI}

$\mathrm{T}_{\mathrm{m}}$ Ortalama absorber plaka sıcaklığ $\left({ }^{\circ} \mathrm{C}\right)$

$\mathrm{T}_{\mathrm{g}}$ Ortalama soğutma suyu giriş sıcaklığı $\left({ }^{\circ} \mathrm{C}\right)$

$\mathrm{T}_{c}$ Ortalama soğutma suyu çıkış sıcaklığı $\left({ }^{\circ} \mathrm{C}\right)$

$\mathrm{T}_{\text {ort }}$ : Ortalama boru hattı sıcaklığı $\left({ }^{\circ} \mathrm{C}\right)$

$\mathrm{T}_{\mathrm{h}}$ Ortalama hava sicaklığ $1\left({ }^{\circ} \mathrm{C}\right)$

I Ortalama 1şınım değeri $\left(\mathrm{W} / \mathrm{m}^{2}\right)$

$\mathrm{V}_{\mathrm{r}}$ Ortalama rüzgar hızı $(\mathrm{m} / \mathrm{s})$

$\mathrm{T}_{\mathrm{i}}$ Boyler ilk sıcaklığ $\left({ }^{\circ} \mathrm{C}\right)$

$\mathrm{T}_{\mathrm{s}}$ Boyler son sıcaklığı $\left({ }^{\circ} \mathrm{C}\right)$

$\mathrm{Q}_{\text {boy }}$ Boyler toplam 1s1 kazanc1 (kcal)

$\mathrm{q}_{\text {boy }}$ Boyler 1sı kazanc1 (W)

$\mathrm{q}_{\mathrm{b}-\mathrm{h}}$ Boru hattından havaya 1sı kaybı (W)

$\mathrm{q}_{\mathrm{t}}$ Absorberden çekilen 1sı (W)

$\mathrm{A}_{\mathrm{p}}$ Absorber alanı ( PV panel alanı ) $\left(\mathrm{m}^{2}\right)$

$\eta_{\text {th }}$ Termal dönüşüm oranı (\%)

$\mathrm{C}_{\mathrm{p}}$ Sabit basınçta özgül ısı $\left(\mathrm{kcal} / \mathrm{kg}{ }^{\circ} \mathrm{C}\right)$

$\rho$ Yoğunluk $\left(\mathrm{kg} / \mathrm{m}^{3}\right)$

m Boyler kütlesi (kg)

$\lambda$ Isı iletkenlik katsayısı (W/mK)

$\mathrm{r}_{2}$ Boru dış yarıçapı $(\mathrm{m})$

$\mathrm{r}_{1}$ Boru iç yarıçapı $(\mathrm{m})$ 


\section{TEŞEKKÜR}

Bu çalışmayı, 2017 FEN-C-DRP-070.317.0111 nolu proje ile destekleyen, Marmara Üniversitesi Bilimsel Araştırma Projeleri Birimi' ne ve proje tesisatı için yer sağlayan, Konya İnnopark yönetimine teşekkür ederiz.

\section{KAYNAKLAR}

[1] Sirinivas, M., Jayaraj, S., ( 2013 ). Investigation on the performans of double pass hybrid - type ( PV/T ) solar air heater. International Journal of Energy and Environment, 4, 687698.

[2] Dubey S, Sarvaiya J.N, Seshadri B., (2013). Temperature dependent photovoltaic ( PV ) efficiency and its effect on PV production in The World - a review, Energy Procedia, 33:311-321

[3] Alizadeh H, Ghasempour R, Shafii M.B, Ahmadi M.H, Yan W.M, Nazari M.A., (2018). Numerical simulation of PV cooling by using single turn pulsating heat pipe, International Journal of Heat and Mass Transfer, 127: 203-208.

[4] Rawat P, Debbarma M, Mehrotra S, Sudhakar K., ( 2014 ). Design, Development and Experimental Investigation of Solar Photovoltaic/ Thermal ( PV/T ) Water Collector System, International Journal of Science, Environment and Technology, 3,3, 1173-1183.

[5] Sanjeev J, Soni M.S, Gakkhar N., (2016). Parametric modeling and simulation of photovoltaic panels with earth water heat exchanger cooling, Geothermal Energy, 4:10
[6] Muzathik, A.M. (2014 ). Photovoltaic modules operating temperature estimation using a simple correlation. International Journal of Energy Engineering, 4,151-158.

[7] Kalogirou, S.A. and Tripanagnostopoulos, Y. ( 2006 ). Hybrid $\mathrm{PV} / \mathrm{T}$ solar systems for domestic hot water and electricity production. Energy Conversion \&Management 47, 33683382.

[8] Rekha, L. Vijayalakshmi, M.M. and Natarajan, E. ( 2013 ). Photovoltaic thermal hybrid solar system for residental applications. International Journal of Research in Engineering and Technology, 2,10,277-283.

[9] Hossain M.S, Pandey A.K, Selvaraj J, Rahim N.A, Rivai A, Tyagi V.V., (2019). Thermal performance analysis of parallel serpentine flow based photovoltaic/thermal (PV/T) system under composite climate of Malaysia, Applied Thermal Engineering, 153, 861-871.

[10] Duffie, J.A. and Beckman, W.A. ( 1980 ). Solar engineering of thermal processes. J. Wiley\&Sons,

[11] Atmaca M, Pektemir I.Z and Y1lmaz E., (2018).Investigation of possibilities obtain heating, hot water and electricity from same solar panel by means of a new design called "Solenam" ( Solar Energy Absorber Machine ) 432 3.International Multidisciplinary Studies Congress Kiev, Ukrain,, pp 156-166.

[12] Atmaca M and Pektemir I.Z., (2019). An Investigation on the Effect of the Total Efficiency of Water and Air Used Together as aWorking Fluid in the Photovoltaic Thermal Systems, Processes,7,516, pp 1-19 